\title{
Geographic patterns of cigarette butt waste in the urban environment
}

\author{
Maacah Marah, Thomas E Novotny
}

Graduate School of Public Health, San Diego State University, San Diego, California, USA

\section{Correspondence to}

Maacah Marah, Graduate School of Public Health, San Diego State University, Hardy Tower 119, 5500 Campanile Drive, San Diego, CA 92182-4162 USA; marah@usc.edu

I am one author signing on behalf of all co-owners of the contribution.

Received 15 December 2010 Accepted 23 February 2011

\begin{abstract}
Background This reports the initial phase of a study to quantify the spatial pattern of cigarette butt waste in an urban environment.

Methods Geographic Information Systems (GIS) was used to create a weighted overlay analysis model which was then applied to the locations of businesses where cigarettes are sold or are likely to be consumed and venues where higher concentrations of butts may be deposited. The model's utility was tested using a small-scale litter audit in three zip codes of San Diego, California.

Results We found that cigarette butt waste is highly concentrated around businesses where cigarettes are sold or consumed. The mean number of butts for predicted high waste sites was 38.1 (SD 18.87), for predicted low waste sites mean 4.8 (SD 5.9), $\mathrm{p}<0.001$. Conclusions Cigarette butt waste is not uniformly distributed in the urban environment, its distribution is linked to locations and patterns of sales and consumption. A GIS and weighted overlay model may be a useful tool in predicting urban locations of greater and lesser amounts of cigarette butt waste. These data can in turn be used to develop economic cost studies and plan mitigation strategies in urban communities.
\end{abstract}

\section{INTRODUCTION}

Tobacco product waste (TPW) poses a significant, quantifiable problem in urban waste control. The cigarette filter, a plastic, non-biodegradable component of cigarette butt waste, is the most resilient part of TPW. In 2007, 1.35 trillion filtered cigarettes were manufactured and over 360 billion were consumed in the USA. ${ }^{1}$ On beach and waterway litter clean-ups TPW accounts for the largest single category of litter. ${ }^{2-4}$ Litter audits in a large North American city identified TPW as 10\% of the items counted. ${ }^{5}$

Cigarette filters are composed primarily of cellulose acetate, a non-biodegradable plastic material. Cellulose acetate is photodegradable, and under ideal conditions, ultraviolet rays may break the filter into smaller pieces. However, the total amount of cellulose acetate is not reduced by such degradation and continues to exist in the environment. ${ }^{6}$ The leachates from cigarette butts in an aquatic environment are toxic to several types of aquatic organisms and, when accidentally consumed, also to pets, wildlife and humans. ${ }^{7} 8$ Finally, the cost of cigarette butt clean-up is significant. Schneider et al in San Francisco estimated it to be US\$6098969 in 2009. ${ }^{9}$

Given that cigarette butts are likely to be classified as toxic waste, are present in large numbers and may require substantial resources to remove them from the environment, they clearly represent to communities an economic externality of smoking ${ }^{10}$ - that is, smoking carries a cost that is borne by people who are not involved with smoking. Strategies to address this problem could require that those who directly benefit from smoking-tobacco companies, cigarette retailers and smokers-become responsible for the cost of cigarette butt clean-up. To determine the burden of cigarette butt waste in the environment and to aid in assessing clean-up costs, tools are needed to conveniently estimate how this waste is concentrated. In California, state law prohibits smoking in nearly all indoor venues (except tobacco shops and cigar bars ${ }^{11}$ ). Thus, the outdoor environment near certain venues might offer the highest concentration of discarded TPW. This paper reports on the initial test of a tool in San Diego, California, that does not require specific litter collection or audits, to develop geographic data on cigarette butt waste.

\section{METHODS}

To develop a variable list of potential high TPW locations, researchers created a list of venues where cigarettes are often sold or consumed. A ninequestion survey was then administered to members of a volunteer organisation that conducts street litter clean-ups. This survey contained questions about types of litter and locations of TPW. The following seven sites were identified as generally having the highest concentrations of TPW on streets and sidewalks adjacent to them: bars, convenience (7-11 type stores) and liquor stores, cafes (such as Starbucks), gas stations, grocery stores, restaurants and traffic signal-guarded street crossings.

The geographic parameter was zip codes, and a database of venues by zip code was developed. Geographic boundaries and traffic signal shapefiles were downloaded from SanGIS, a San Diego City/ County GIS data source (http://www.sangis.org/) For the remaining variables, data were collected through online searches of businesses. To assist with this, students from a local high school's Regional Occupation Program performed online data collection of business addresses in the city of San Diego.

Using ArcGIS 9.3 software (ESRI, 2009, Environmental Systems Research Institute http://www. esri.com/software/arcgis/index.html) the locations of bars, convenience stores, cafes, gas stations, grocery stores and restaurants were geocoded. At this point, three zip codes were selected on which to test the model. These zip codes met a number of criteria. First, they had an appropriate number of unlocked scheme, see http://

about/unlocked.xhtml 
each venue of interest necessary to create a robust model and, second, they did not contain large shopping malls where clean-up of TPW would be performed as part of overall property management. Third, the zip codes were primarily residential but with enough businesses to test the model. Finally, to make the model applicable as broadly as possible they needed to be neither among the wealthiest nor among the poorest areas in the city. The sale price of homes/condos was used as an indicator for assessing relative wealth of the communities, and the zip codes were within $1 \mathrm{SD}$ of the median sale price for the City of San Diego. ${ }^{12}$ As all of the selected zip codes were located in the city of San Diego's older core they are also more representative of the urban environment than of a suburban environment.

The datasets for each of the selected zip codes were then further processed in ArcMAP 9.3 so that a weighted overlay model could be created. For each variable, 10 distance levels were created using the spatial analyst straight line function. Maximum distance was set to 500 feet for bars, cafes and restaurants, and 1000 feet for traffic signals, convenience stores, gas stations and grocery stores. The variables were then reclassified using the spatial analyst reclassify function. Finally, a weighted overlay model was created using the spatial analyst weighted overlay tool. Based on survey results of locations that had large amounts of TPW, influence for variables was set to $25 \%$ for bars, $20 \%$ for convenience stores, $15 \%$ for cafes and $10 \%$ for each remaining variable. In other words, as bars were expected to generate the largest amount of TPW they were given the highest value in the model. Thus, a location with one bar would be equivalent to a location with a café and restaurant. This model generated maps of the zip codes with predicted gradations of TPW concentration. High TPW sites contained a concentration of venues at which TPW was likely to be generated, low TPW sites fell completely outside the influence of these venues (see figure 1).

Field butt counts were done to confirm the results of the weighted overlay analysis model at locations predicted to have either a high or low level of TPW. These counts occurred over two consecutive days in September 2010. Street cleaning schedules were checked to ensure that recent cleaning would not affect the counts. At each location, a hierarchy of decisions was followed to select the exact point to be sampled. When a bar or convenience store was identified, the sampling area was the entire sidewalk and 5 feet into the street directly in front of the business entrance and 10 feet on either side. When a bar or convenience store was not present, the northeast corner of an intersection was selected. In these cases, the sampling area was created by counting butts 10 feet in either direction from the corner's apex and then 5 feet into the street and along the entire sidewalk that fell within this 20 -foot length. In all, 25 points of predicted high TPW and 26 points of predicted low TPW were sampled.

The means of the number of butts counted in predicted high and low count sites were compared using a two-tailed t test.

\section{RESULTS}

For the 25 sites predicted by the model to be high TPW sites, the mean number of butts collected was 38.1 (range 11-77, SD 18.9). For the 26 sites predicted by the model to be low TPW sites, the mean number of butts collected was 4.8 (range 0-26, SD 5.9), with six sites having no butts. These mean counts were significantly different as measured by $t$ test $(p<0.001)$. The weighted overlay model for one of the zip codes is shown in figure 1.

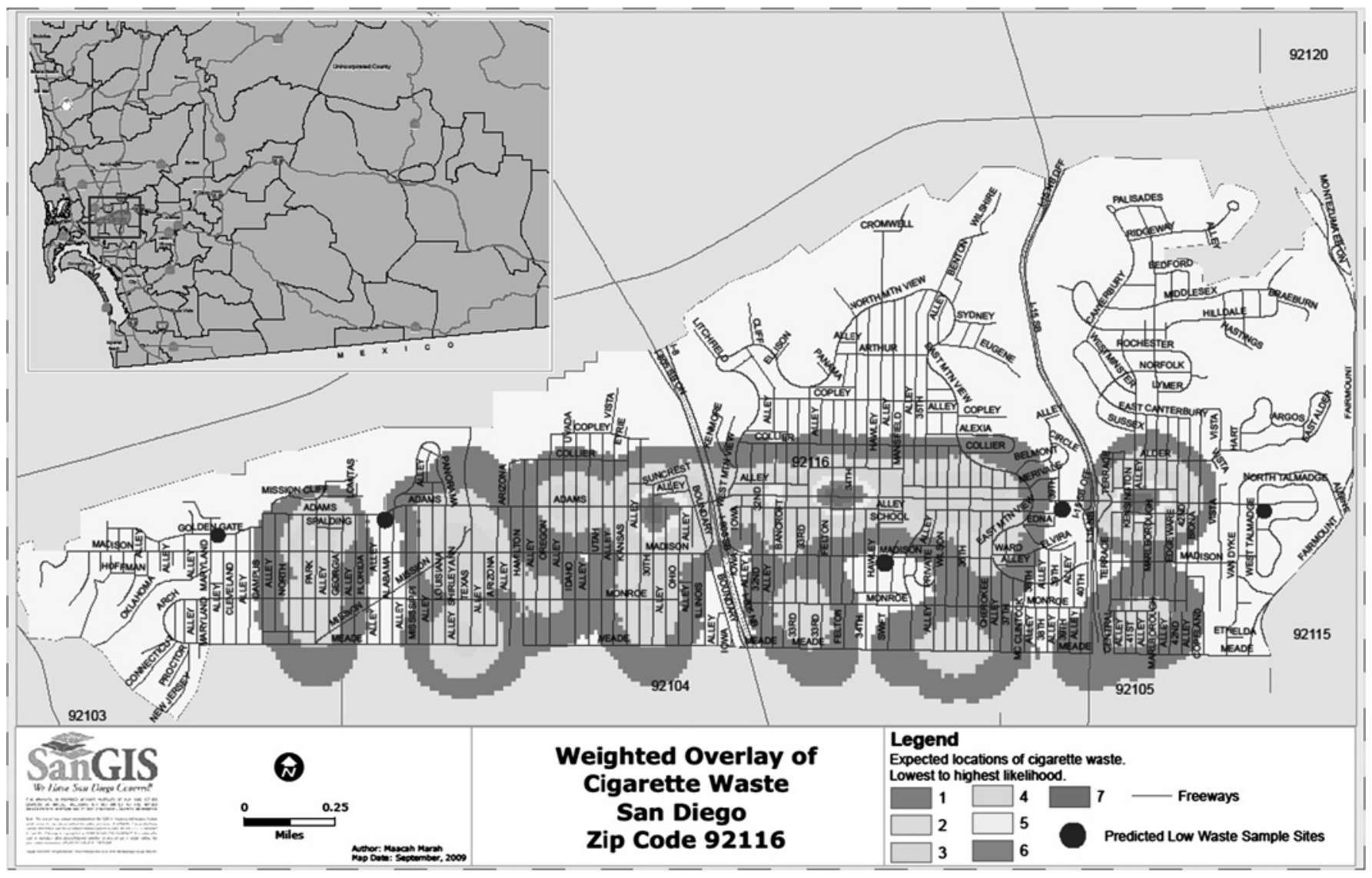

Figure 1 Weighted overlay model of cigarette butt waste, San Diego County zip code 92116. 


\section{DISCUSSION}

We developed a model for predicting areas of high and low amounts of TPW based on publicly available information via online searches for businesses by zip code and GIS shapefiles. Testing the model in three mixed-use urban zip codes showed that the model accurately predicted areas of high and low TPW. As expected, greater numbers of butts were found near venues that sell cigarettes or where they are generally consumed. Additional testing of the model in other communities will allow us to develop a model to estimate counts of butts by venue. Further confirmation of the estimates could then be made with formal litter audits, but in general this model may provide a useful tool for cities to estimate cigarette butt burdens and even clean-up costs using GIS methodology.

Bars and convenience stores were given the largest weight in the model and field data collection supported this weighting. However, field notes indicate that among bars and convenience stores there was considerable variation in the level of butts. This variation appeared to be due, in part, to business owner responsibility: some businesses are more aggressive about butt clean-up. It is worth noting that most bars had placed containers for cigarette butts outside for their patrons' use, yet many people chose to litter their butts on the ground. Further testing of the model might permit grouping venues into 'very high butt waste' and 'high butt waste' categories. It would also be important to explore the difference between these two groups with respect to observed smoker and proprietor behaviour to understand how better to tune our model for more variable predictors in different zip codes.

This pilot study was limited as we tested the model's fit with actual clean-up data only in three primarily residential zip codes, and therefore this test may not be applicable in other types of neighbourhoods such as industrial or downtown areas. Nevertheless, we believe that our GIS tool may be important in quantifying the concentration of TPW in the urban environment so that economic, regulatory and educational efforts might be targeted to high-waste-generating venues and businesses. We plan to further develop this tool as part of a larger butt waste mitigation project in California; we hope to apply the tool to a variety of communities, verify the accuracy of the tool in predicting butt waste burdens and publish community-specific estimated butt waste burdens in California.

\section{CONCLUSION}

This study demonstrates the potential utility of a weighted overlay GIS model of cigarette butt waste concentration in an urban environment. Systematically documenting locations of
TPW is important for guiding mitigation efforts and recognising the burden that TPW places on communities. Although cigarette butts are almost ubiquitous in the urban environment, there is a strong correlation between high concentrations of TPW and points of cigarette purchase and consumption. Recommendations for butt waste mitigation using data generated by this tool might be developed. These could include:

1. New regulatory policies for management of waste by business owners where this waste is generated.

2. Better enforcement of existing litter laws. If enforcement efforts are stepped up, would this impact some stores' decision to sell cigarettes and potentially reduce the number of outlets selling cigarettes?

3. Collaboration with the business community to improve awareness of the burden of butt waste and the responsibility of venues to reduce the burden of this waste near them.

Acknowledgements We would like to thank Mark Abbott and the students of Patrick Henry High School for help with data collection.

Competing interests None.

Provenance and peer review Not commissioned; externally peer reviewed.

\section{REFERENCES}

1. US Department of Agriculture. Tobacco Outlook Report. Economic Research Service, 2007. http://usda.mannlib.cornell.edu/MannUsda/viewDocumentInfo.do? document $\mid D=1389$ (accessed 24 Sep 2010).

2. Oigman-Pszczol SS, Creed JC. Quantification and classification of marine litter on beaches along Armacao dos Buzios, Rio de Janeiro, Brazil. J Coast Res 2007:23:421-8.

3. Martinez-Ribes L, Basterretxea G, Palmer M, et al. Origin and abundance of beach debris in the Balearic Islands. Sci Mar 2007;71:305-14.

4. Ocean Conservancy. International Coastal Cleanup 2010 Report. The Ocean Conservancy, 2010. http://www.oceanconservancy.org/our-work/marine-debris/ program marinedebris iccreport.html (accessed 25 Nov 2010).

5. HDR. The City of San Francisco Street Litter Re-Audit 2008. HDR Engineering/Brown, Vence \& Associates, Inc./MGM Management. http://www.sfenvironment.org/ downloads/library/2008_litter_audit.pdf (accessed 20 Nov 2010).

6. Hon NS. Photodegradation of cellulose acetate fibers. J Polym Sci A Published Online First: March 1977;15:725-44. doi: 10.1002/pol.1977.170150319.

7. Register K. Cigarette butts as litter-toxic as well as ugly? Bull Am Litt Soc 2000;25:23-9.

8. Micevska T, Warne MS, Palo F, et al. Variation in, and causes of toxicity of cigarette butts to a cladoceran and microtox. Arch Environ Contam Toxicol 2006;50:205-12.

9. Health Economics Consulting Group. Cost of Tobacco Litter in San Francisco. Health Economics Consulting Group, 2009. http://www.sfenvironment.org/ our_programs/program_info.html?ssi=3 (accessed 5 Sep 2009).

10. Novotny TE, Zhao F. Consumption and production waste: another externality of tobacco use. Tob Control 1999;8:75-80.

11. Technical Assistance Legal Center. Tobacco Laws Affecting California. 2009 http://www.phlpnet.org/sites/phlpnet.org/files/Tobacco\%20Laws\%20Affecting\% 20California\%20\%28Booklet\%29_3_09.pdf (accessed 12 Feb 2011).

12. Data Quick News. San Diego Union Tribune Zip Code Chart. http://www.dqnews com/Charts/Monthly-Charts/SDUT-Charts/ZIPSDUT.aspx (accessed 13 Dec 2010). 